\title{
Bone Signaling in Middle Ear Development: A GenomeWide Differential Expression Analysis
}

Nielsen, Michelle Christine; Bertelsen, Tomas Martin; Friis, Morten; Winther, Ole; FriisHansen, Lennart; CayéThomasen, Per; Sørensen, Mads Sølvsten

\section{Published in:}

Anatomical Record

Link to article, DOI:

10.1002/ar.22992

Publication date:

2014

Document Version

Publisher's PDF, also known as Version of record

Link back to DTU Orbit

Citation (APA):

Nielsen, M. C., Bertelsen, T. M., Friis, M., Winther, O., FriisHansen, L., CayéThomasen, P., \& Sørensen, M. S. (2014). Bone Signaling in Middle Ear Development: A GenomeWide Differential Expression Analysis.

Anatomical Record, 297(12), 2349-2355. https://doi.org/10.1002/ar.22992

\section{General rights}

Copyright and moral rights for the publications made accessible in the public portal are retained by the authors and/or other copyright owners and it is a condition of accessing publications that users recognise and abide by the legal requirements associated with these rights.

- Users may download and print one copy of any publication from the public portal for the purpose of private study or research.

- You may not further distribute the material or use it for any profit-making activity or commercial gain

- You may freely distribute the URL identifying the publication in the public portal 


\title{
Bone Signaling in Middle Ear Development: A Genome-Wide Differential Expression Analysis
}

\author{
MICHELLE CHRISTINE NIELSEN, ${ }^{1 *}$ TOMAS MARTIN BERTELSEN, ${ }^{2}$ \\ MORTEN FRIIS, ${ }^{1}$ OLE WINTHER, ${ }^{2,3}$ LENNART FRIIS-HANSEN, ${ }^{4}$ \\ PER CAYÉ-THOMASEN, ${ }^{1,5}$ AND MADS SØLVSTEN SØRENSEN ${ }^{5}$ \\ ${ }^{1}$ Department of Otorhinolaryngology, Head \& Neck Surgery and Audiology, Rigshospitalet, \\ University of Copenhagen, Copenhagen, Denmark \\ ${ }^{2}$ Department of Biology and Biotech Research and Innovation Centre, The Bioinformatics \\ Centre, Faculty of Science, University of Copenhagen, Copenhagen, Denmark \\ ${ }^{3}$ DTU Informatics, Technical University of Denmark, Copenhagen, Denmark \\ ${ }^{4}$ Center for Genomic Medicine, Rigshospitalet, University of Copenhagen, Copenhagen, \\ Denmark \\ ${ }^{5}$ Department of Otorhinolaryngology, Head and Neck Surgery, Gentofte Hospital, \\ University of Copenhagen, Hellerup, Denmark
}

\begin{abstract}
Common middle ear diseases may affect bone behavior in the middle ear air cell system. To understand this pathologic pneumatization, the normal development of bone in the middle ear should be investigated. The objective of this study was to analyze gene expression of bone-related signaling factors and gene sets in the developing middle ear. Microarray technology was used to identify bone-related genes and gene sets, which were differentially expressed between the lining tissue of adult (quiescent) bulla and young (resorbing/forming) bulla. Data were analyzed using tools of bioinformatics and expression levels of selected genes were validated using quantitative polymerase chain reaction. The candidate gene products were compared with previously published data on middle ear bone metabolism. No differentially expressed genes were found on the outer surface of bulla. On the inner lining a total of 260 genes were identified of which 22 genes were involved in bone metabolism. Gene set analysis revealed five enriched bone-related gene sets. The identified differentially expressed bone-related mRNAs and gene sets are of potential significance in the normally developing bulla. These factors and gene sets may also play important roles during pathologic pneumatization of the middle ear air cell system in common middle ear diseases. In addition, this study suggests that the control of growth rate and wall thickness from resorptive as well as formative signals all originate from the inner lining cells of the bulla wall. Anat Rec, 297:2349-2355, 2014. (C) 2014 Wiley Periodicals, Inc.
\end{abstract}

Key words: microarray analysis; air cell development; bone modeling; rat bulla

Additional Supporting Information may be found in the online version of this article.

Grant sponsor: The Danish Hospital Foundation for Medical Research, Region of Copenhagen and Døvefonden.

*Correspondence to: Michelle Christine Nielsen; Department of Otorhinolaryngology, Head and Neck Surgery and Audiology,
F2074, Rigshospitalet, University of Copenhagen, Blegdamsvej 9, 2100 Copenhagen, Denmark. E-mail: mcras@hotmail.com

Received 12 March 2014; Accepted 27 May 2014.

DOI 10.1002/ar.22992

Published online 16 July 2014 in Wiley Online Library (wileyonlinelibrary.com). 
Localized bone growth, modeling and remodeling of the middle ear air cell system (MEACS) result from the activity of osteoclasts and osteoblasts acting in concert. In common pathological conditions, such as chronic suppurative otitis media and cholesteatoma, this balance is obviously disturbed. In order to understand pathologic MEACS remodeling, the mechanisms responsible for normal physiological control must be determined.

Bone is a hard tissue, consisting of living osteocytes in a cellular network embedded in a tough, mineralized intercellular matrix. For this reason any change of bone size and shape must occur through surface resorption and surface formation. This involves the combined action of separate surface populations of osteoclasts and osteoblasts acting in concert. The signals required for this coordination may originate from bone related peptides expressed in the associated soft lining tissue (functional matrix). Several studies have investigated the otic capsule (Moss, 1961; Frenz and Van De Water, 1991) and skull base (Moss et al.,1987; Richards and Jabbour, 2011) morphology from this perspective. In MEACS development the effects of a dysfunctional tuba, (Hormann, 1986) an altered air pressure, (Wolfman and Chole, 1986) inflammation (Ikarashi et al., 1994) or infection (Caye-Thomasen et al., 1999) may result from bone modeling events triggered by peptide signaling lining cells.

Previously, sequential fluorochrome-labeling in rabbits, has documented how the bone of the bulla wall grows by bone resorption by osteoclasts on the inner surface of the bulla (IB) and concurrent bone formation by osteoblasts on the outer surface of the bulla (OB) (Sorensen et al., 1992). In a recent study, a baseline growth plot of rat bullar volume was calculated, showing how bullar development is taking place in the early stages of life. The resorption and formation was peaking in young (10 days old) and completed in adult (80 days old) rats (Mey et al., 2006) (Fig. 1). Signals that induce resorption are expected to be higher at the inner bullar surface at 10 days compared to the corresponding signals at 80 days. Consequently, by comparing normalized gene array results between 10 and 80 days, the gene products involved in bone resorption may stand out as differentially expressed, while gene product unrelated to resorption remain unchanged. A similar mechanism may apply bone formation on the outer surface. With gene arrays it may be possible to determine the role and importance of the individual gene and gene set for middle ear bone signaling.

In this study, gene transcription levels were measured for bullar bone lining cells in rats on resorbing, forming and quiescent surfaces using microarrays covering the entire rat genome. Differentially expressed genes and enriched gene sets were identified to find gene products and pathways with a potential for middle ear signaling.

\section{MATERIALS AND METHODS \\ Animals}

Twelve Lewis inbred rats (Charles River) 10 days old and 12 Lewis inbred rats (Charles River) 80 days old, were preanaesthetized with inhalation of Halothane $3 \%$. Surgical anesthesia was induced by Brevimytal Natrium $500 \mathrm{mg}$ (Lilly, Giesen, Germany), $55 \mathrm{mg} / \mathrm{kg}$ body weight, i.p. Following thoracotomy, the heart was opened at the

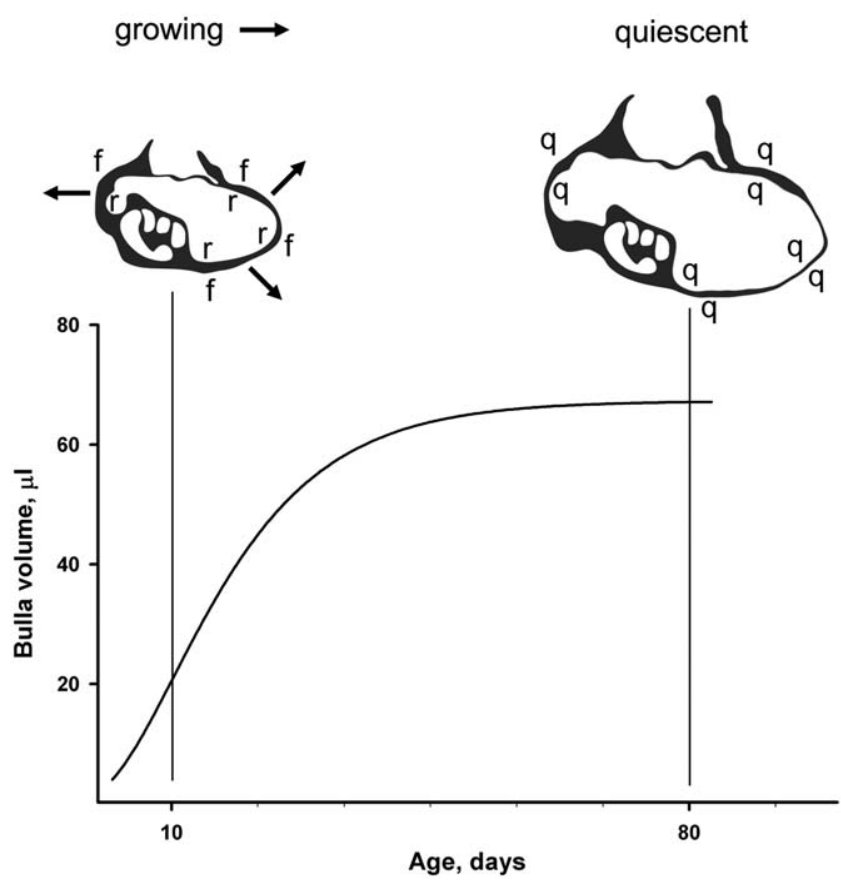

Fig. 1. Growth plot of rat bulla volume versus age and diagrams of a growing (10 days) and quiescent (80 days) rat bullae. The young bulla grows with resorption $(r)$ by osteoclasts on the inner surface and formation $(f)$ by osteoblasts on the outer surface of the bulla. The adult bulla has quiescent $(q)$ surfaces. Arrows indicate the direction of osseous drift movements.

apex, a self-retaining cannula inserted into the left ventricle and the right atrium was opened. The animals were vascular perfused and exsanguinated with isotonic saline. The skull was removed and divided in the midline. Next, the temporal bones were isolated and the bulla exposed. The outer and inner lining tissues of the bulla were meticulously isolated and immersed in RNALater $^{\circledR}$ (Ambion).

The experiment was conducted in a humane manner and in accordance with all local, state, and federal guidelines for the care and utilization of laboratory animals. It was approved by the Ethical Committee for Animal Studies (Dyreforsøgstilsynet) and the local animal department and complied with the NIH Guiding Principles in the Care and Use of animals. All animals had access to uncontaminated, wholesome, palatable food and potable, uncontaminated water in sufficient quantity to maintain the normal condition and weight of the animals. The animals were housed in an environment with a daily light cycle.

\section{Transcript Profiling}

Tissue from each age group was pooled into three groups of four rats making three biological replicates. Tissue from the same age group was separated into outer and inner lining tissue of the bulla. Messenger RNA was extracted using trizol and six hybridizations were performed on the microarray platform Affymetrix GeneChip $^{\circledR}$ Rat Genome 230 2.0. Each tissue type from each group had a single hybridization and two round amplifications starting from $100 \mathrm{ng}$ total RNA. 
TABLE 1. Differentially expressed genes related to bone metabolism in inner bulla

\begin{tabular}{lll}
\hline Probe set Id & \multicolumn{1}{c}{ Gene name } & Gene symbol \\
\hline NM_053822_at & S 100 calcium binding protein A8 & S100a8 \\
NM_053663_at & Versican & Vcan \\
NM_031808_at & Calpain 6 & Capn6 \\
NM_053587_at & S 100 calcium binding protein A9 & S100a9 \\
NM_133514_at & Matrix metallopeptidase 10 & Mmp10 \\
NM_001076134_at & Collagen, type IV, alpha 2 & Col4a2 \\
NM_001135009_at & Collagen, type IV, alpha 1 & Col4a1 \\
NM_012929_at & Collagen, type II, alpha 1 & Col2a1 \\
XM_001076840 & Collagen, type XI, alpha 1 & Col11a1 \\
NM_031825_at & Fibrillin 1 & Fbn1 \\
NM_001107189_at & Tenascin N & Tnn \\
NM_017066_at & Pleiotrophin & Ptn \\
NM_001108318_at & ATPase, H ${ }^{+}$transporting, lysosomal V1 subunit A & Atp6v1a \\
NM_012636_at & Parathyroid hormone-like hormone & Pthlh \\
NM_031135_at & Kruppel-like factor 10 & Klf10 \\
NM_024141_at & Dual oxidase 2 & Duox2 \\
NM_053963_at & Matrix metallopeptidase 12 & Mmp12 \\
NM_012938_at & Cathepsin E & Ctse \\
NM_012522_at & Cystathionine beta synthase & Cbs \\
NM_001012089_at & Dual specificity protein phosphatase 2 & -5.0 \\
NM_017325_at & Runt related transcription factor 1 & Dusp2 \\
NM_138513_at & Calcitonin-related polypeptide, beta & Runx1 \\
\hline
\end{tabular}

${ }^{\text {a } F o l d ~ C h a n g e . ~ N e g a t i v e ~ v a l u e s ~ r e p r e s e n t ~ g e n e s ~ u p r e g u l a t e d ~ o n ~ t h e ~ s u r f a c e ~ i n ~ y o u n g ~ i n n e r ~ b u l l a ~ c o m p a r e d ~ w i t h ~ a d u l t ~ i n n e r ~}$ bulla samples and positive values represent genes upregulated on the surface in adult inner bulla compared with young inner bulla.

Microarray hybridizations, scanning and image preprocessing was done by the Microarray Center of Copenhagen University Hospital. The microarray data were made available in the ArrayExpress database (http:// www.ebi.ac.uk/arrayexpress) under accession number EMTAB-2336.

\section{Preprocessing of Microarray Data}

All microarray data computations were done with Bioconductor 2.8 (Gentleman et al., 2004) using R (R Development Core Team, 2011) retrieved from http://www.Rproject.org/. For improved gene expression signal a custom chip definition file (BrainArray v. 14.0.0) was used for updated probe-to-RefSeq gene transcript mappings (Dai et al., 2005). Probe sets were summarized to RefSeq gene expression values using the GC-RMA algorithm (Wu et al., 2004) with least-varying-set (LVS) normalization (Calza et al., 2008).

\section{Single Gene Differential Analysis}

Of all genes, $16 \%$ were discarded as nonexpressed on all arrays using the FLUSH procedure (Calza et al., 2007) with GC-RMA background subtraction. This increased the statistical power of testing for differentially expressed genes between young and adult IB and $\mathrm{OB}$, respectively. The moderated t-test from the Limma software package was applied to each gene and the obtained P-values were corrected for multiple testing using the Benjamini-Hochberg algorithm to control the False Discovery Rate (FDR) at 5\%.

The differentially expressed genes were analyzed using DAVID web tools (v. 6.7, http://www.david.abcc. ncifcrf.gov/).

\section{Gene Set Enrichment Analysis}

Gene set analysis (Luo et al., 2009) was performed as planned comparison tests focusing on prespecified gene sets (public) and novel bone-related gene sets.

Public gene sets were selected from the two databases MSigDB v. 3.0 and NetPath. MSigDB provided two relevant gene sets: (1) Gene Ontology (Ashburner et al., 2000) (v. 2008) term "BONE_REMODELING" and (2) Biocarta (http://www.biocarta.com) RANKL pathway. NetPath provided RANKL Signaling Pathway (Raju et al., 2011) as three gene sets.

Novel gene sets were manually curated based on previously published documentation of genes involved in bone resorption and bone formation. Genes were annotated "up" or "down" while assigned to five novel gene sets: (1) Osteoclast related genes, (2) bone dissolving, (3) osteoclast differentiation, (4) osteoclast migration, adhesion, and polarization, and (5) osteoblast related genes. Genes comprising sets (1) and (5) were chosen with general agreement on the role of these genes. Furthermore, the public BONE_REMODELING gene set was refined by dividing it into resorptive and formative genes annotated by up or down. Public gene sets were mapped from human to rat orthologous gene symbols by InParanoid database. A $P$ value cutoff of 0.05 was used to indicate significantly enriched gene sets for each of the two comparisons (IB and OB for adult vs. young). Further details in supplementary.

\section{Validation of the Array Findings}

Quantitative polymerase chain reaction (qPCR) was performed using the High Capacity cDNA Reverse Transcription Kit (Applied Biosystems, Foster City, CA) 


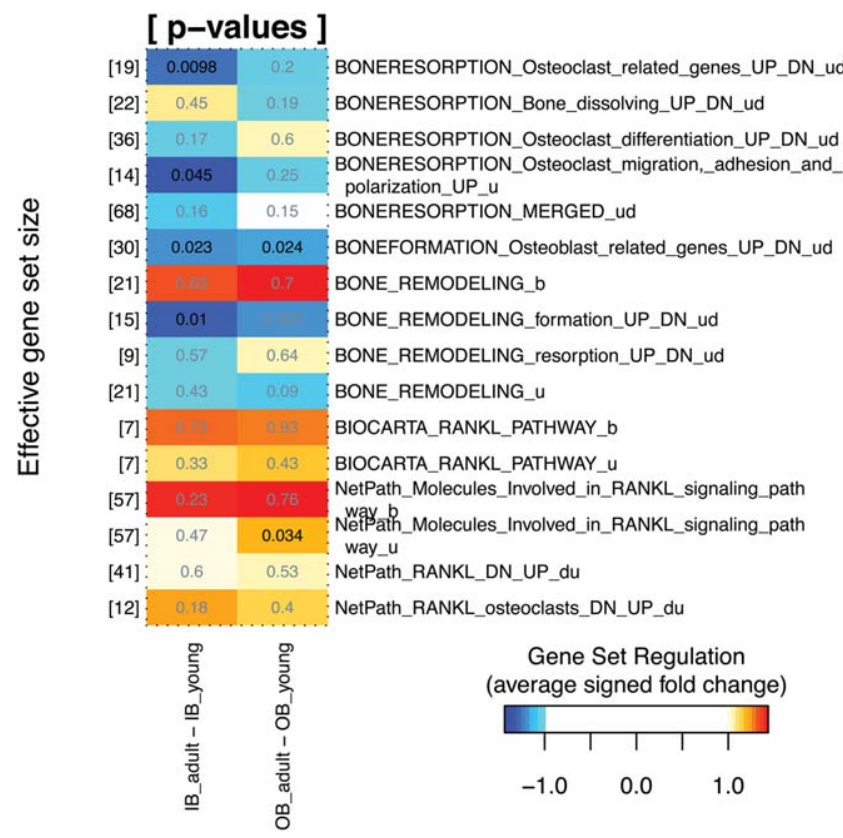

Fig. 2. Gene set analysis with bone-related gene sets. Five gene sets were significantly enriched (black numbers) $(P<0.05)$. Enriched gene sets from the inner surface of the bulla (IB) and outer surface of the bulla $(\mathrm{OB})$ from young (10 days old) and adult rats ( 80 days old) were compared (IB_adult-IB_young) and (OB_adult-OB_young). The results revealed both enriched formative and resorptive gene sets on the IB. The red (blue) colour indicates up (down) gene set regulation in adult bulla compared with young bulla. Enrichment of gene sets relied on overall concordance with 'up' and 'down' gene annotations in the gene set, as indicated by suffixes ' $u$ ' or ' $d$ ', respectively. For gene sets without gene annotations two aspects of enrichment were analysed: Coordinate up (or down) regulation of all genes (suffix ' $u$ '), or bidirectional regulation (suffix 'b') for which both up and down differential gene expression was counted as concordant with an increased gene set regulation.

according to the manufacturer's instructions. A $200 \mathrm{ng}$ total RNA from each of the RNA pools was reverse transcribed. The expression of the transcripts was quantified using the following assays (Qiagen, Germany): s 100 calcium binding protein A8 (S100a8, QT00402969), calpain 6 (Capn6, QT00180768), s 100 calcium binding protein A9 (S100a9, QT00175693), matrix metallopeptidase 10 (Mmp10, QT01568028), fibrillin 1 (Fbn1, QT00187215), tenascin N (Tnn, QT01570478), parathyroid hormonelike hormone (Pthlh, QT00374766), kruppel-like factor 10 (Klf10, QT01800582), calcitonin-related polypeptide, beta (Calcb, QT00191709), tumor necrosis factor (ligand) superfamily, member 11 (RANKL) (Tnfsf11, QT00195125). The expression was quantitated and normalized to the expression of beta-actin as previously described (Friis et al., 2011). The validated proteins were chosen based on fold change (FC) or relevance to previously published middle ear data.

\section{RESULTS \\ Bone-Related Single Gene Products}

Single gene analysis of the microarray identified 260 significant differentially expressed genes when adult (quiescent) IB was compared with young (resorbing) IB

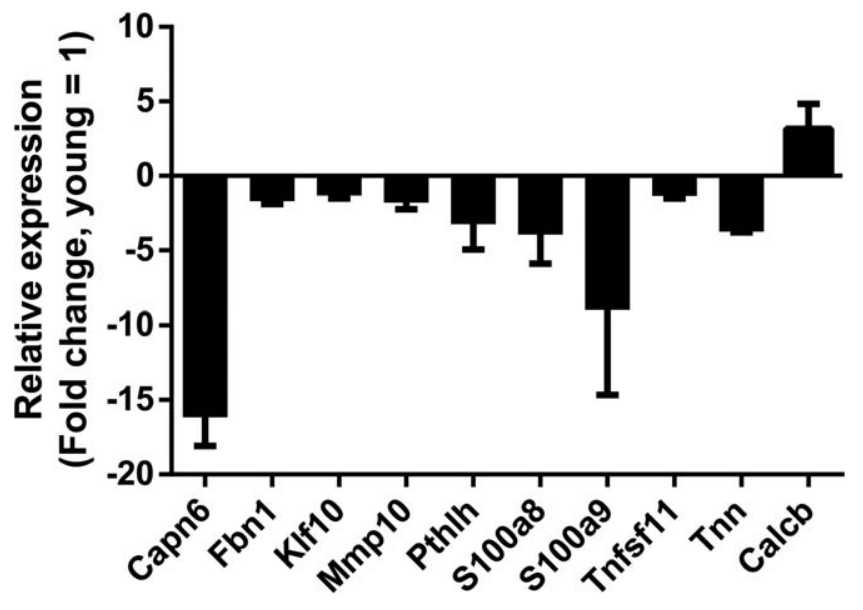

Fig. 3. Validation of the differentially expressed genes. Differentially expressed bone related genes from the inner bulla. The expression of ten transcripts identified in the array was validated using quantitative polymerase chain reaction (qPCR). The qPCR confirmed all the chosen transcripts. The figure shows the fold change in expression of the adult rat compared to that in the young. All shown changes were significant $(P<0.05)$.

$(\mathrm{FDR}<0.05)$. Of these 260 genes, 224 were known and 36 were of unknown function. In all, 22 genes were identified specific for the bone metabolism on IB (known or novel). The FC and the individual probe set/gene related to bone metabolism are shown in Table 1. No significant differentially expressed genes were found on OB.

\section{Bone-Related Gene Sets}

Gene set analysis of all the measured genes against bone-related gene sets identified five enriched gene sets $(P<0.05)$. Three gene sets were enriched on IB, one gene set was enriched on $\mathrm{OB}$ and one gene set was enriched in both comparisons (Fig. 2).

\section{Validation}

The qPCR confirmed the microarray results of the following chosen transcripts; Capn6, Fbn1, Klf10, Mmp10, Pthlh, S100a8, S100a9, Tnn, and Calcb. The qPCR also found receptor activator of nuclear factor kappa-B ligand (RANKL/Tnfsf11) upregulated on the young IB compared with the adult IB (Fig. 3).

\section{DISCUSSION}

The present study is a genome-wide microarray analysis of bone lining cells from the normal developing rat bulla aiming to identify bone-related candidate genes and gene sets in the MEACS. FDR was used to assess significance: If a gene product value is highly variable even a large FC between, for example, young and adult IB might represent only chance variation, and not a true biological difference. However, if stochastic variation is small, even a slight difference may be significant. By analyzing statistically the internal variance of triple measurements the differentially expressed genes could be identified with a specified risk of error in case of larger as well as smaller FCs. The single gene analysis identified 22 differentially expressed genes related to 
bone metabolism when adult (quiescent) IB was compared with young (resorbing) IB $(\mathrm{FDR}<0.05)$. Other genes may be biologically relevant if they work together as a functional group even if they fail to reach significance when analyzed separately: a differential group effect may become significant only when the corresponding group members are analyzed together as a gene set. Thus, a gene set analysis on public and novel gene sets was done. This identified five enriched bone-related gene sets $(P<0.05)$.

In the following paragraphs some proteins and gene sets of particular interest are discussed. They were selected on a fold change or relevance to previously published results.

\section{Proteins Previously Highlighted in Publications on Middle Ear Bone Metabolism}

Matrix metalloproteinases (MMPs) are a family of zinc-dependent endopeptidases. Recently, a study based on oligonucleotide microarray analyses identified upregulation of MMP10 in cholesteatoma extracellular matrix using retroauricular skin as control (Kwon et al., 2006). MMP10 has also been documented in osteoclasts in osteophytic bone and neonatal ribs in a study using immunohistochemistry and in situ zymography (Bord et al., 1998). This study demonstrated an upregulation of MMP10 (FC-5.0). The MMP10 seems to play a role as a regulator of bone resorption in pathological and healthy MEACS and may potentially have a bonesignaling function.

Tenascins (TNs) are extracellular matrix glycoproteins. There are four members of the TN family: TNC, TNR, TNX, and TNN. Tenascins have previously been implicated in middle ear signaling, but the immunohistochemical tools used in the studies did not allow discrimination between the four members (Lang et al., 1997; Juhasz et al., 2009). In the present study, the TNN was upregulated in young IB (FC -5.0) and may have a possible bone-signaling role in the middle ear.

\section{Novel Bone-Related Proteins of the Middle Ear}

Calcium-binding protein molecule A8 (S100A8) and calcium-binding protein molecule A9 (S100A9) are involved in the regulation of a number of cellular processes. They are localized in the cytoplasm and/or nucleus of a wide range of cells including osteoblasts and osteoclasts (Zreiqat et al., 2007). Recently, S100A8 was shown to stimulate osteoclast differentiation and activity during space flight (Sambandam et al., 2010). In this study S100A8 (FC - 25.0) and S100A9 (FC - 16.7) were upregulated in young IB implicating a potential effect on the osteoblasts and osteoclasts in the normal growing MEACS.

Calpains (CAPNs) form a group of 14 members of calcium-sensitive cysteine proteases. In a biochemical study CAPN I and II were suggested to participate in the middle ear bone resorption associated with cholesteatoma by their involvement in collagen destruction (Amar et al., 1996). In addition, CAPN6 has been identified as a regulator of osteoclastic bone resorption via cytoskeletal organization and microtubule acetylation (Hong et al., 2011). In the present study a significant upregulation of CAPN6 $(-16.7)$ in young IB was demonstrated.

Fibrillin-1 (FBN1) is an extracellular matrix glycoprotein that is altered in Marfan syndrome, characterized by, for example, defects in the skeletal system. Recently, FBN1 and FBN2 were found to be implicated in bone formation through a process involving the regulation of local TGF $\beta$ and bone morphogenetic protein signals (Nistala et al., 2010). In accordance with these results, this study showed an upregulation of FBN1 on young IB (FC -5.0 ). Therefore, FBN1 may be a medium range signaling protein for coupled bone formation on OB.

Calcitonin-related polypeptide (CALC) is a neuropeptide which exists in two forms, CALCA and CALCB. The MEACS might be under control of the nervous system as denervation resulted in bone resorption inside the bulla of the Mongolian gerbil (Sherman and Chole, 1996; Sherman and Chole, 1999; Sherman and Chole, 2001). This was assumed to result from the blocking of catecholamines but also due to inhibition of neuropeptides such as substance $\mathrm{P}$ and nerve growth factor (Sherman and Chole, 1995). In the present study, CALCB was significant differentially upregulated in adult IB (FC 1.8) in accordance with the suggested role of this neuropeptide as an inhibitor of osteoclast resorption (Yamamoto et al., 1986).

The bulla of the rat is a hollow bony structure. During development the growing bulla maintains a constant 60 $\mu \mathrm{m}$ wall thickness. Consequently a dynamic equilibrium exists between the resorbing osteoclasts acting on IB and the forming osteoblasts acting on OB. The signals that link and adjust resorption and formation on opposing bony surfaces are unknown. Forming and resorbing signals might be generated on $\mathrm{OB}$ and $\mathrm{IB}$, respectively. Alternatively, all rate controlling signals might originate only on one side, either the outside or the inside to coordinate cellular activities on both sides simultaneously through short- and medium range signaling. In this study no differentially expressed single genes were identified on the OB. This finding favors a location of the basic rate controlling growth signal at the IB. Theoretically, a short range resorptive signal might control bone resorption on the inner bullar surface, while a coupled medium range formative signal might reach the outer surface through the bullar wall via the lacunocanalicular porosity or the cellular osteocytic network at a $60 \mu \mathrm{m}$ distance (Drossopoulou et al., 2000). This may explain how a constant wall thickness is maintained even when the rate of resorption varies.

The present study demonstrated differential expression of osteoblast related proteins like S100A8, S100A9, and FBN. It also showed osteoclast related proteins like; MMP10, TNN, S100A8, S100A9, CAPN6, and CALCB on the IB surface. Some of the factors have previously been reported in the middle ear literature (Amar et al., 1996; Lang et al., 1997; Kwon et al., 2006; Juhasz et al., 2009) while others are new candidate genes in MEACS modeling. Furthermore, the novel gene sets "osteoclast related genes", "osteoblast related genes" and the formative genes comprising the public gene set "BONE REMODELING" were also significantly enriched on the IB. This indicates that the controlling signals originate on the inside and that the genes work in functional groups.

Differentially expressed signals may be overlooked for a number of reasons. Individual osteoclasts are very 
effective and the process of resorption may proceed at a high rate with only a few active osteoclasts involved. Besides, important bone-related genes may be lost through attenuation by dilution as they may be found only in the smaller fraction of the lining tissue, which represents the osteoclast domain in close contact with the bone surface. Future isolation of such microscopic subpopulations of lining cells may be possible with the laser microdissection technique (Markaryan et al., 2011).

Furthermore, signaling proteins may be secreted in a cyclical pattern rather than continually and some signaling proteins may reach the lining cells via an opposite route from within the lacuna-canalicular system.

Finally, in this study the levels of mRNA expression determined were assumed to correspond to the levels of protein abundance (transcriptional control). In the pathway from DNA to RNA to protein the gene expression can be regulated at many steps. Some studies show results with limited correlations between mRNA and protein expression levels (Greenbaum et al., 2003). This may result from another level of regulation of gene expression or because of stochastic noise in mRNA and protein expression experiments. However, for most genes transcriptional controls are thought to be paramount as only this kind of control ensures that no superfluous intermediates are synthesized.

The qPCR validation confirmed all the microarray results except for RANKL. The qPCR result of RANKL was contrary to the array data significant. Thus, independent validation of microarray data continues to be an important consideration.

The present study of lining tissue in the normal developing bulla identified several differentially expressed genes and gene sets of potential significance. These factors and gene sets may also play important roles during pathologic pneumatization of the middle ear air cell system in common middle ear diseases. Furthermore, resorptive as well as formative signals may all originate from IB lining cells. Future array studies on young animals with experimental otitis compared to the present results may offer important clinical information by demonstrating which of the differentially expressed gene products are responsible for the decreased pneumatization caused by otitis media. Furthermore, future studies should include other methodologies, for example, miRNA and proteomics analyses. This may reveal more information about the bone metabolism in the MEACS and verify the observed changes of gene expression in this study.

\section{ACKNOWLEDGMENTS}

The authors would like to acknowledge Klaus Qvortrup, Copenhagen Ear Research Centre, University of Copenhagen, Denmark.

\section{LITERATURE CITED}

Amar MS, Wishahi HF, Zakhary MM. 1996. Clinical and biochemical studies of bone destruction in cholesteatoma. J Laryngol Otol 110:534-539.

Ashburner M, Ball CA, Blake JA, Botstein D, Butler H, Cherry JM, Davis AP, Dolinski K, Dwight SS, Eppig JT, Harris MA, Hill DP, Issel-Tarver L, Kasarskis A, Lewis S, Matese JC, Richardson JE, Ringwald M, Rubin GM, Sherlock G. 2000. Gene ontology: tool for the unification of biology. The Gene Ontology Consortium. Nat Genet 25:25-29.

Bord S, Horner A, Hembry RM, Compston JE. 1998. Stromelysin-1 (MMP-3) and stromelysin-2 (MMP-10) expression in developing human bone: potential roles in skeletal development. Bone 23:712.

Calza S, Raffelsberger W, Ploner A, Sahel J, Leveillard T, Pawitan Y. 2007. Filtering genes to improve sensitivity in oligonucleotide microarray data analysis. Nucleic Acids Res 35:e102.

Calza S, Valentini D, Pawitan Y. 2008. Normalization of oligonucleotide arrays based on the least-variant set of genes. BMC Bioinformatics 9:140.

Caye-Thomasen P, Hermansson A, Tos M, Prellner K. 1999. Bone modeling dynamics in acute otitis media. Laryngoscope 109:723729.

Dai M, Wang P, Boyd AD, Kostov G, Athey B, Jones EG, Bunney WE, Myers RM, Speed TP, Akil H, Watson SJ, Meng F. 2005. Evolving gene/transcript definitions significantly alter the interpretation of GeneChip data. Nucleic Acids Res 33:e175.

Drossopoulou G, Lewis KE, Sanz-Ezquerro JJ, Nikbakht N, McMahon AP, Hofmann C, Tickle C. 2000. A model for anteroposterior patterning of the vertebrate limb based on sequential longand short-range Shh signalling and Bmp signalling. Development 127:1337-1348.

Frenz DA, Van De Water TR. 1991. Epithelial control of periotic mesenchyme chondrogenesis. Dev Biol 144:38-46.

Friis M, Martin-Bertelsen T, Friis-Hansen L, Winther O, Henao R, Sorensen MS, Qvortrup K. 2011. Gene expression of the endolymphatic sac. Acta Otolaryngol 131:1257-1263.

Gentleman RC, Carey VJ, Bates DM, Bolstad B, Dettling M, Dudoit S, Ellis B, Gautier L, Ge Y, Gentry J, Hornik K, Hothorn T, Huber W, Iacus S, Irizarry R, Leisch F, Li C, Maechler M, Rossini AJ, Sawitzki G, Smith C, Smyth G, Tierney L, Yang JY, Zhang J. 2004. Bioconductor: open software development for computational biology and bioinformatics. Genome Biol 5:R80.

Greenbaum D, Colangelo C, Williams K, Gerstein M. 2003. Comparing protein abundance and mRNA expression levels on a genomic scale. Genome Biol 4:117.

Hong JM, Teitelbaum SL, Kim TH, Ross FP, Kim SY, Kim HJ. 2011. Calpain-6, a target molecule of glucocorticoids, regulates osteoclastic bone resorption via cytoskeletal organization and microtubule acetylation. J Bone Miner Res 26:657-665.

Hormann K. 1986. Effect of tubal function on the osseous structures of the petrous bone. An animal experiment study. HNO 34:202207.

Ikarashi F, Nakano Y, Okura T. 1994. The relationship between the degree of chronic middle ear inflammation and tympanic bulla pneumatization in the pig as animal model. Eur Arch Otorhinolaryngol 251:100-104.

Juhasz A, Sziklai I, Rakosy Z, Ecsedi S, Adany R, Balazs M. 2009. Elevated level of tenascin and matrix metalloproteinase 9 correlates with the bone destruction capacity of cholesteatomas. Otol Neurotol 30:559-565.

Kwon KH, Kim SJ, Kim HJ, Jung HH. 2006. Analysis of gene expression profiles in cholesteatoma using oligonucleotide microarray. Acta Otolaryngol 126:691-697.

Lang S, Schilling V, Wollenberg B, Mack B, Nerlich A. 1997. Localization of transforming growth factor-beta-expressing cells and comparison with major extracellular components in aural cholesteatoma. Ann Otol Rhinol Laryngol 106:669-673.

Luo W, Friedman MS, Shedden K, Hankenson KD, Woolf PJ. 2009. GAGE: generally applicable gene set enrichment for pathway analysis. BMC Bioinformatics 10:161.

Markaryan A, Nelson EG, Hinojosa R. 2011. Duplex real-time PCR assay for quantifying mitochondrial DNA deletions in laser microdissected single spiral ganglion cells. Methods Mol Biol 755:315326.

Mey KH, Sorensen MS, Homoe P. 2006. Histomorphometric estimation of air cell development in experimental otitis media. Laryngoscope 116:1820-1823.

Moss ML. 1961. Rotation of the otic capsule in bipedal rats. Am J Phys Anthropol 19:301-307. 
Moss ML, Vilmann H, Moss-Salentijn L, Sen K, Pucciarelli HM Skalak R. 1987. Studies on orthocephalization: growth behavior of the rat skull in the period 13-49 days as described by the finite element method. Am J Phys Anthropol 72:323-342.

Nistala H, Lee-Arteaga S, Smaldone S, Siciliano G, Carta L, Ono RN, Sengle G, Arteaga-Solis E, Levasseur R, Ducy P, Sakai LY Karsenty G, Ramirez F. 2010. Fibrillin-1 and -2 differentially modulate endogenous TGF-beta and BMP bioavailability during bone formation. J Cell Biol 190:1107-1121.

Raju R, Balakrishnan L, Nanjappa V, Bhattacharjee M, Getnet D, Muthusamy B, Kurian TJ, Sharma J, Rahiman BA, Harsha HC Shankar S, Prasad TS, Mohan SS, Bader GD, Wani MR, Pandey A. 2011. A comprehensive manually curated reaction map of RANKL/RANK-signaling pathway. Database (Oxford) 2011 bar021.

Richards GD, Jabbour RS. 2011. Foramen magnum ontogeny in Homo sapiens: a functional matrix perspective. Anat Rec (Hoboken) 294:199-216.

Sambandam Y, Blanchard JJ, Daughtridge G, Kolb RJ, Shanmugarajan S, Pandruvada SN, Bateman TA, Reddy SV. 2010 Microarray profile of gene expression during osteoclast differentiation in modelled microgravity. J Cell Biochem 111:1179-1187.

Sherman BE, Chole RA. 1995. A mechanism for sympathectomyinduced bone resorption in the middle ear. Otolaryngol Head Neck Surg 113:569-581.
Sherman BE, Chole RA. 1996. In vivo effects of surgical sympathectomy on intramembranous bone resorption. Am J Otol 17:343346.

Sherman BE, Chole RA. 1999. Effect of pharmacological sympathectomy on osteoclastic activity in the gerbilline auditory bulla in vivo. Ann Otol Rhinol Laryngol 108:1078-1087.

Sherman BE, Chole RA. 2001. Effect of chemical sympathectomy with 6-hydroxydopamine on osteoclast activity in the gerbilline middle ear bulla. Otol Neurotol 22:237-241.

Sorensen MS, Jorgensen MB, Bretlau P. 1992. Drift barriers in the postcartilaginous development of the mammalian otic capsule. Eur Arch Otorhinolaryngol 249:56-61.

Wolfman DE, Chole RA. 1986. Osteoclast stimulation by positive middle-ear air pressure. Arch Otolaryngol Head Neck Surg 112: 1037-1042.

Wu Z, Irizarry R, Gentleman R, Martinez-Murillo F, Spencer F. 2004. A model-based background adjustment for oligonucleotide expression arrays. J Am Stat Assoc 99:909-917.

Yamamoto I, Kitamura N, Aoki J, Shigeno C, Hino M, Asonuma K, Torizuka K, Fujii N, Otaka A, Yajima H. 1986. Human calcitonin gene-related peptide possesses weak inhibitory potency of bone resorption in vitro. Calcif Tissue Int 38:339-341.

Zreiqat H, Howlett CR, Gronthos S, Hume D, Geczy CL. 2007. S100A8/S100A9 and their association with cartilage and bone. J Mol Histol 38:381-391. 